\title{
Distinct Profiles of Anxiety and Dysphoria during Spontaneous Withdrawal from Acute Morphine Exposure
}

\author{
Patrick E Rothwell', Mark J Thomas' and Jonathan C Gewirtz*,' \\ 'Graduate Program in Neuroscience and Departments of Neuroscience and Psychology, University of Minnesota, Minneapolis, MN, USA
}

\begin{abstract}
The negative motivational aspects of withdrawal include symptoms of both anxiety and depression, and emerge after termination of chronic drug use as well as after acute drug exposure. States of acute withdrawal are an inherent part of intermittent drug use in humans, but the contribution of acute withdrawal to the development of addiction has received limited systematic investigation, because of a lack of preclinical models for withdrawal states that emerge spontaneously after acute drug exposure. Here, we have characterized a spontaneous increase in the magnitude of the acoustic startle reflex (ie, spontaneous withdrawal-potentiated startle) that emerges after acute morphine administration in rats, and compared the time course of startle potentiation and place conditioning. We find that startle potentiation seems to be related to a decrease in opiate receptor occupancy and reflects an anxiety-like state with a pharmacological profile similar to other signs of opiate withdrawal. Spontaneous startle potentiation emerges before the rewarding effects of morphine have subsided, even though naloxone administration after a single morphine exposure causes both startle potentiation and conditioned place aversion (CPA). These results show that negative emotional signs of withdrawal develop after just one exposure to morphine, and are likely a recurrent aspect of intermittent drug use that may contribute to the earliest adaptations underlying the development of addiction. Furthermore, the dissociation between spontaneous startle potentiation and CPA suggests anxiogenic and dysphoric manifestations of opiate withdrawal may be mediated by distinct neural mechanisms that are progressively engaged as withdrawal unfolds.
\end{abstract}

Neuropsychopharmacology (2009) 34, 2285-2295; doi:I 0. I038/npp.2009.56; published online 3 June 2009

Keywords: morphine; withdrawal; anxiety; dysphoria; acoustic startle; place conditioning

\section{INTRODUCTION}

The negative motivational aspects of withdrawal from chronic drug exposure contribute to the maintenance of established drug addiction (Koob and Le Moal, 2008), but negative emotional states also emerge after acute drug exposure (Breiter et al, 1997; Kirby and Stitzer, 1993; Van Dyke and Byck, 1982). These episodes of acute withdrawal are a recurrent and integral component of human drug use (Baker et al, 2004), emerging after occasional drug use or when ongoing drug intake is interrupted by sleep or periods when drug supply is limited (Dole et al, 1966; Haertzen and Hooks, 1969). Alleviation of acute withdrawal may motivate further drug use, and changes in neural activity during acute withdrawal could contribute to drug-induced alterations in physiology and brain function (Houshyar et al, 2003; Houshyar et al, 2004). Withdrawal from acute opiate exposure can be precipitated by opiate receptor antagonists

*Correspondence: Dr JC Gewirtz, Psychology and Neuroscience, University of Minnesota, 75 East River Road, Minneapolis, MN 55455, USA, Tel: + 612625 6653, Fax: +6126262079,

E-mail: jgewirtz@umn.edu

Received 12 March 2009; revised 25 April 2009; accepted 26 April 2009 (for review, see Harris and Gewirtz, 2005), but in the context of human opiate abuse, withdrawal emerges spontaneously in the absence of an antagonist. Despite this fact, surprisingly few preclinical models have been developed to study the spontaneous emergence of withdrawal after acute opiate exposure. This study describes distinct profiles of anxiety and dysphoria in rats that emerge spontaneously after acute exposure to morphine.

Withdrawal from chronic drug use produces symptoms of both anxiety and depression, including restlessness, irritability, dysphoria, and anhedonia (American Psychiatric Association, 2000; Haertzen and Hooks, 1969). The acoustic startle reflex is a validated measure of anxiety in both animals and humans (Lang et al, 2000), and is elevated in rodents during spontaneous withdrawal from acute morphine exposure (ie, withdrawal-potentiated startle; Harris and Gewirtz, 2004a). Other spontaneous signs of acute morphine withdrawal in rodents, including conditioned place aversion (CPA) (Bechara et al, 1995) and increased thresholds for intracranial self-stimulation (ICSS) (Liu and Schulteis, 2004), may reflect states of dysphoria or anhedonia associated with depression (Barr et al, 2002; Carlezon and Chartoff, 2007; Land et al, 2008b). Given the growing number of experimental dissociations between anxiety- and depression-like behavior in rodents 
(Bosch et al, 2008; Land et al, 2008a; Nestler and Carlezon, 2006; Sahuque et al, 2006; Wallace et al, 2009), as well as distinctions between clinical disorders of anxiety and depression (American Psychiatric Association, 2000; Goldberg, 2008; Kessler et al, 2008; Krueger, 1999), it is important to distinguish between these specific negative affective components of opiate withdrawal, as they may not necessarily coincide with one another.

To address these issues, we have further characterized spontaneous withdrawal-potentiated startle and compared its time course with that of spontaneous CPA. We show that spontaneous withdrawal-potentiated startle seems to be related to a decrease in opiate receptor occupancy and has an anxiety-like pharmacological profile that resembles other measures of opiate withdrawal. However, startle potentiation emerges while rats still exhibit conditioned place preference (CPP), showing an increase in anxiety-like behavior before the rewarding effects of morphine have subsided. In contrast, withdrawal-potentiated startle and CPA develop concurrently when withdrawal is precipitated by naloxone (an opiate receptor antagonist). These results indicate that anxiogenic and dysphoric manifestations of acute morphine withdrawal reflect changes in distinct neural systems. These negative emotional states accompany the earliest stages of drug exposure, are likely a recurrent feature of intermittent drug use in humans, and thus may contribute significantly to the development of addiction.

\section{MATERIALS AND METHODS}

\section{Subjects}

Male Sprague-Dawley rats (Harlan) were housed in groups of 4-5 in metal cages with a $12 \mathrm{~h}$ light-dark cycle (light on 0800-2000 hours) and free access to food and water except during testing. Rats were allowed to acclimate to housing conditions for 2 weeks after arrival, were gently handled for two consecutive days before any testing, and weighed 250$350 \mathrm{~g}$ at the beginning of each experiment. All procedures conformed to the National Institutes of Health Guide for the Care and Use of Laboratory Animals and were approved by the University of Minnesota Institutional Animal Care and Use Committee.

\section{Drugs}

Morphine sulfate was provided by the National Institute on Drug Abuse (Rockville, MD). Naloxone, chlordiazepoxide, and R,S-propranolol hydrochlorides were obtained from Sigma (St. Louis, MO). LY235959 was obtained from Tocris (Ellisville, MO). All drugs were dissolved in $0.9 \%$ saline (except propranolol, which was dissolved in water) and injected (i.p.) in a volume of $1 \mathrm{ml} / \mathrm{kg}$ body weight. Over the course of these studies, we shifted to s.c. administration of morphine and naloxone to be consistent with the majority of other work in this field (Houshyar et al, 2003; Houshyar et al, 2004; Schulteis et al, 1994). We directly compared i.p. and s.c. morphine injections in several experiments and found no significant differences between routes of administration (data not shown), so results from both routes of administration have been pooled. All drug doses are expressed as the weight of the salt.

\section{Acoustic Startle}

Acoustic startle was tested in four identical plastic cages $(17 \times 8.5 \times 11 \mathrm{~cm})$ resting on compression springs and located within individual ventilated sound-attenuating chambers. Cage movement resulted in displacement of a piezoelectronic accelerometer (Model ACH-01, Measurement Specialties, Valley Forge, PA) attached to each cage. Voltage output from the accelerometer was filtered and amplified by a custom-built signal processor, digitized on a scale of arbitrary units ranging from 0-1000 (National Instruments SCB100 and PCI-6071E boards), and recorded using Matlab (The MathWorks, Natick, MA). Startle amplitude was defined as the peak accelerometer voltage during the first $200 \mathrm{~ms}$ after onset of the startle stimulus. High-frequency speakers (Radio Shack Supertweeters, range $=5-40 \mathrm{kHz}$ ) located $10 \mathrm{~cm}$ beside each cage delivered the startle stimuli, which were $50-\mathrm{ms}$ bursts of filtered white noise (low pass: $22 \mathrm{kHz}$, rise-decay $<5 \mathrm{~ms}$ ) at intensities of 95 or $105 \mathrm{~dB}$. Ventilating fans elevated background noise to $\sim 60 \mathrm{~dB}$.

Acoustic startle was tested on each of 2 days before drug exposure. For each test session, rats were placed in the startle chambers for a 5-min acclimation period, and then presented with 40 startle stimuli (20 each at 95 or $105 \mathrm{~dB}$ in semi-random order) with a 30-s inter-stimulus interval. Average startle amplitudes from the second day were used to match animals into experimental groups with similar overall mean startle amplitudes. Each day of drug testing began with a baseline startle session before any drug injections. Several experiments involved startle testing over multiple days using Latin Square or crossover designs; details are provided in figure legends. All drug injections were given in the colony, and rats remained in their home cage between drug injections and startle tests.

\section{Place Conditioning}

Our place conditioning apparatus and procedure were developed according to published recommendations (Bardo and Bevins, 2000; Carlezon, 2003; Cunningham et al, 2006). The apparatus consists of a rectangular plastic cage $(40 \times 20 \times 20 \mathrm{~cm})$ divided into two sides by a central partition. Each side has a distinct floor texture and wall color: metal bars paired with white walls, and wire mesh paired with black striped walls. Each rat's position within the apparatus was monitored by an overhead video camera connected to a computer running AnyMaze software (Stoelting, Wood Dale, IL).

Rats were transported to the place conditioning room and allowed to acclimate for at least $10 \mathrm{~min}$ before every experimental session. Each experiment began with a 10 -min baseline session in which rats were free to move between both sides of the apparatus. The rats used in these studies spent an average of $320 \mathrm{~s}(53.4 \%)$ on the bar side during the baseline session; two rats with $>75 \%$ baseline preference for one side were excluded from further study. The side of the apparatus paired with drug treatment was counterbalanced within each experiment, yielding an unbiased procedure in which rats spend $\sim 50 \%$ of the baseline session on the side to be paired with drug. 
Daily conditioning sessions began $24 \mathrm{~h}$ after the baseline session. Details concerning the number, duration, and order of conditioning sessions are provided in figure legends. Twenty-four hours after the last conditioning session, a 10min test session was conducted in which rats were free to move between both sides of the apparatus. We chose to express place conditioning results in terms of percent time spent on the drug-paired side, rather than using a difference score measured in seconds, because percentage measures are relatively independent of the length of the testing session and thus facilitate comparisons across studies.

\section{Data Analysis}

Startle data were collapsed across both intensities (95/ $105 \mathrm{~dB}$ ) before statistical analysis (Harris and Gewirtz, 2004a), as the magnitude of withdrawal-potentiated startle was not affected by stimulus intensity (data not shown). In each experiment, we first conducted one-way analysis of variance (ANOVA) to verify similar baseline startle amplitude between experimental groups; there were no differences in baseline startle between groups in any experiment (data not shown). Changes in startle after morphine administration were calculated as percent change from baseline on the same day (Walker and Davis, 2002b). For experiments that utilized a crossover design, baseline startle amplitude was similar on both days of testing, so an average baseline value was used to calculate percent change on each individual day. An area under the curve measure for total withdrawal severity was calculated for each individual subject by adding together percent change in startle across all time points tested; mean and standard error were then calculated for all subjects in each group.

All data were analyzed using factorial ANOVA, with repeated measures on within-subject factors. For main effects or interactions involving repeated measures, the Huynh-Feldt correction was applied to control for potential violations of the sphericity assumption. Significant interactions were followed with tests for simple effects (Keppel and Wickens, 2004). When appropriate, significant main effects were followed with polynomial trend analysis. All statistical analysis was conducted using SPSS (version 13.0) with a Type I error rate of $\alpha=0.05$ (two-tailed). Group sizes for each experiment are indicated in figure legends.

\section{RESULTS}

\section{Startle Time Course During Spontaneous and Naloxone- Precipitated Withdrawal}

Startle was tested $2-5 \mathrm{~h}$ after acute administration of morphine $(10 \mathrm{mg} / \mathrm{kg})$, with some rats receiving naloxone $(2.5 \mathrm{mg} / \mathrm{kg})$ just before the 2:00 startle test (Figure 1a). Startle was significantly potentiated $4-5 \mathrm{~h}$ after injection of morphine alone, consistent with our earlier report that also showed startle returns to baseline $6 \mathrm{~h}$ after this dose of morphine (Harris and Gewirtz, 2004a). Naloxone caused an immediate but transient potentiation of startle at 2:00, with no change from baseline $3-5 \mathrm{~h}$ after morphine injection (Naloxone $\times$ time interaction: $F_{3,78}=12.19, p<0.001$ ). This dose of naloxone was selected based on our earlier work (Harris et al, 2004b) in an effort to completely displace a
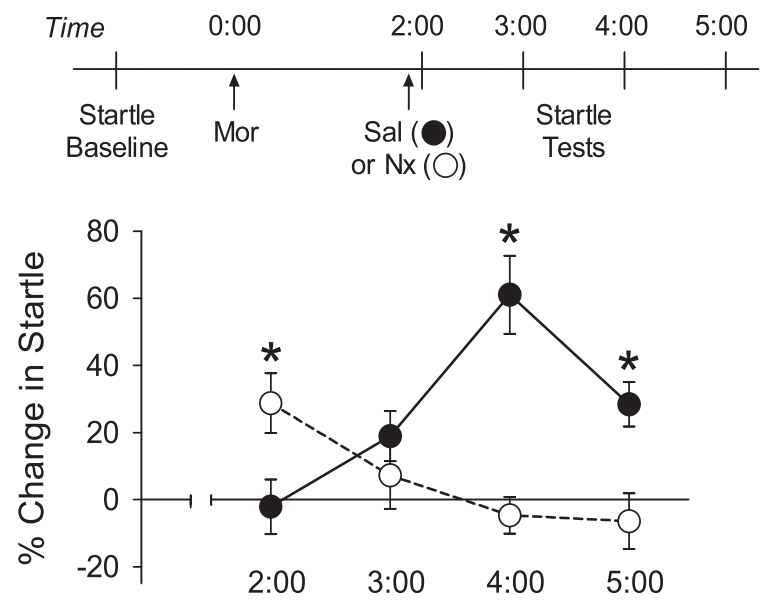

Hours after Morphine
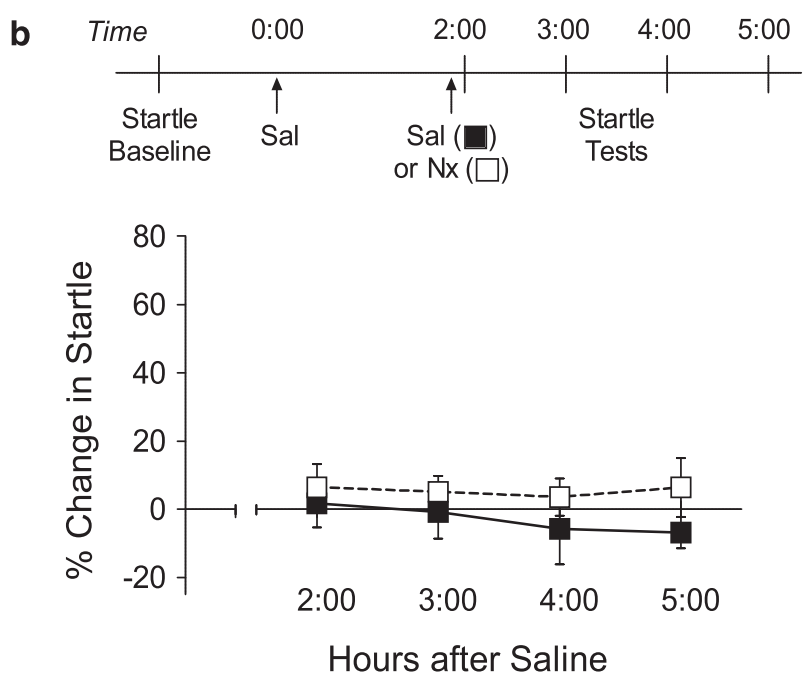

Figure I Startle time course during spontaneous and naloxoneprecipitated withdrawal from acute morphine administration. (a) Top: Experimental timeline - baseline startle was tested before initial injection of morphine (Mor; $10 \mathrm{mg} / \mathrm{kg}$ ), followed $2 \mathrm{~h}$ later by injection of naloxone (Nx; $2.5 \mathrm{mg} / \mathrm{kg}$ ) or saline (Sal). Startle was tested 2, 3, 4, or $5 \mathrm{~h}$ after initial injection. Bottom: Percent change in startle after injection of Mor alone (filled circles) or Mor $+\mathrm{Nx}$ (open circles). (b) Top: Experimental timeline_-parallel control groups were injected with Sal at 0:00. Bottom: Percent change in startle after injection of Sal alone (filled squares) or Sal + $\mathrm{N} \times$ (open squares). Startle was tested at one time point each day over the course of 4 days using a Latin Square design; drug treatment remained the same on each day of testing. All data represent mean \pm SEM. * Significant difference between groups (8-16 rats/group).

morphine from the opiate receptor. There were no significant changes in startle after injection of saline or naloxone alone (Figure 1b) (Naloxone $\times$ time interaction, $\left.\mathrm{F}_{3,66}<1\right)$.

It is noteworthy that the peak magnitude of spontaneous withdrawal (4:00: $61.0 \pm 11.6 \%)$ was significantly larger than the peak magnitude of naloxone-precipitated withdrawal (2:00: $29.8 \pm 9.0 \%)\left(t_{28}=2.23, p=0.034\right)$. This difference was more pronounced when comparing total withdrawal severity, measured as area under the curve across all time points tested (spontaneous: $102.2 \pm 19.5 \%$; precipitated: $24.9 \pm 21.0 \%)\left(t_{28}=2.67, p=0.013\right]$. The difference in total 
withdrawal severity was partly driven by the absence of spontaneous startle potentiation at later time points after naloxone administration (Figure $1 \mathrm{~b}$ ).

\section{Morphine Re-Exposure Delays Startle Potentiation}

If startle potentiation represents a withdrawal effect, it should be blocked by re-exposure to morphine (Figure 2a). Indeed, the startle potentiation normally observed $4 \mathrm{~h}$ after an initial morphine injection was prevented by a second injection of morphine $3 \mathrm{~h}$ after initial injection (Figure $2 \mathrm{~b}$ ) (initial injection $\times$ second injection interaction: $\mathrm{F}_{1,32}=$ 11.07, $p=0.002)$. We conducted a second startle test in the same animals $7 \mathrm{~h}$ after the initial injection (Figure $2 \mathrm{c}$ ). Both groups that received a second injection of morphine (ie, $4 \mathrm{~h}$ earlier) showed significant startle potentiation at this time (main effect of second injection: $F_{1,32}=76.11$, $p<0.001$; interaction: $\mathrm{F}_{1,32}<1$ ). Thus, morphine reexposure does not prevent startle potentiation, but delays its onset until opiate receptor occupancy eventually decreases.
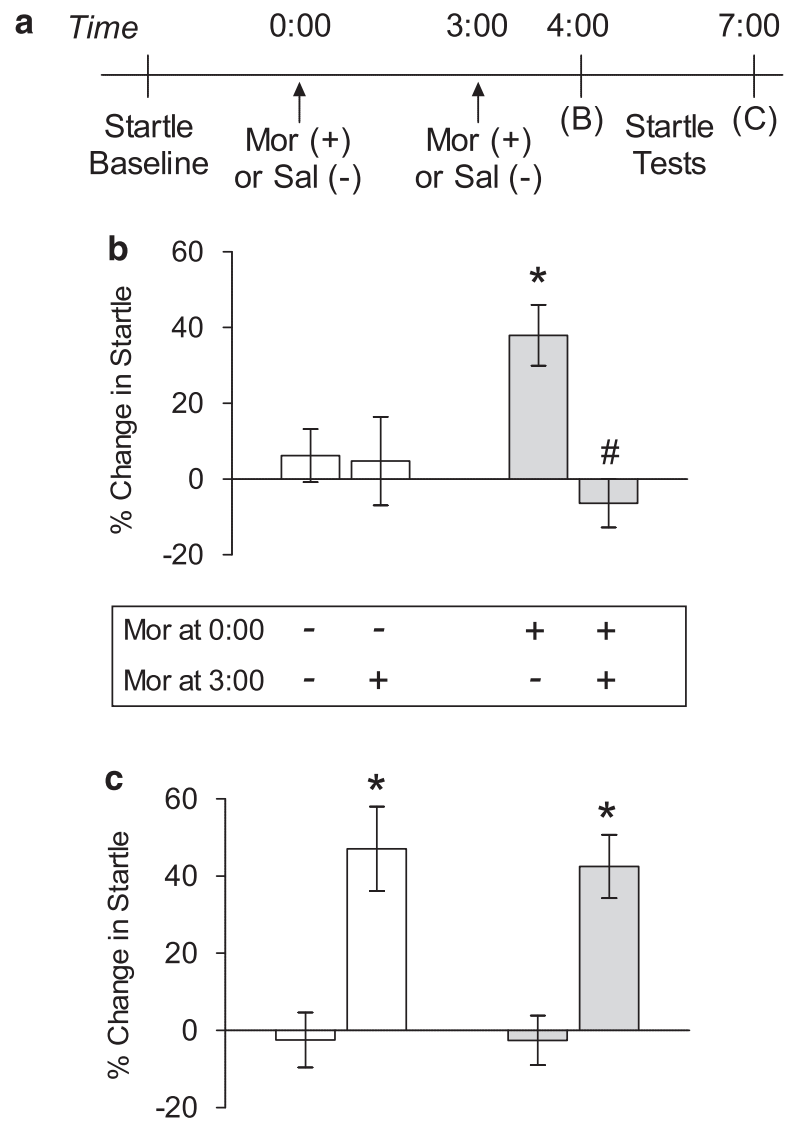

Figure 2 Morphine re-exposure delays the onset of startle potentiation. (a) Experimental timeline: baseline startle was tested before initial injection of morphine (Mor; $10 \mathrm{mg} / \mathrm{kg}$ ) or saline (Sal), followed $3 \mathrm{~h}$ later by a second injection of Mor or Sal. Treatment combinations are shown in the box between panels b and c; gray bars indicate Mor injection at 0:00. (b) Startle test $4 \mathrm{~h}$ after initial injection. (c) Startle test $7 \mathrm{~h}$ after initial injection in the same group of animals. Startle was tested over 2 days using a crossover design; the initial injection was the same on both days, whereas the second injection changed each day in counterbalanced order. *Significant increase compared with saline control group; \# significant decrease compared with morphine alone ( 17 rats/group).
Pharmacological Profile of Spontaneous WithdrawalPotentiated Startle

We next examined whether anxiolytic drugs attenuate spontaneous withdrawal-potentiated startle. Both chlordiazepoxide (a benzodiazepine) and propranolol (a $\beta$-adrenergic receptor antagonist) prevent other forms of startle potentiation (Walker and Davis, 2002a) at the same doses used here $(10 \mathrm{mg} / \mathrm{kg})$, and also decrease anxiety-like behavior in a number of other behavioral paradigms (Cole and Koob, 1988; Harris and Aston-Jones, 1993a, b; Knoll et al, 2007; Rodriguez-Romaguera et al, 2009). Administration of chlordiazepoxide prevented spontaneous withdrawal-potentiated startle (Figure 3a) (morphine $\times$ chlordiazepoxide interaction: $\left.\mathrm{F}_{1,30}=5.49, p=0.026\right)$, as did administration of propranolol (Figure $3 \mathrm{~b}$ ) (morphine $\times$ propranolol interaction: $\left.\mathrm{F}_{1,20}=5.91, p=0.025\right)$. Neither anxiolytic drug affected startle amplitude in the absence of morphine.

NMDA receptor antagonists also prevent signs of opiate withdrawal in rodents (Harris et al, 2008; Kawasaki et al, 2005; Rasmussen, 1995). We examined the effects of LY235959, a competitive NMDA receptor antagonist shown to attenuate precipitated morphine withdrawal (Jones et al, $2002)$, using doses $(1-3 \mathrm{mg} / \mathrm{kg})$ that prevent tolerance to morphine analgesia (Bilsky et al, 1996) and sensitization to morphine-induced locomotion (Mendez and Trujillo, 2008). LY235959 produced a dose-dependent attenuation of startle potentiation (Figure 4) (morphine $\times$ LY235959 interaction: $\left.\mathrm{F}_{2,33}=14.27, p<0.001\right)$. There was a significant linear effect of LY235959 dose after morphine injection $(p=0.012)$, but no effect after saline injection $(p=0.56)$.

\section{Startle Potentiation After The First Morphine Exposure}

As the preceding experiments utilized Latin Square and crossover designs, sometimes involving multiple exposures to morphine, we sought to clarify whether startle was potentiated after the very first exposure to morphine. We pooled control data from the preceding experiments in which startle was tested $4 \mathrm{~h}$ after an animal's first exposure to morphine $(n=33)$ or saline $(n=31)$, and found a highly reliable potentiation of startle after morphine injection $(51.2 \pm 6.6 \%)$ that was significantly greater than the change in startle after saline injection $\left(5.3 \pm 4.6 \% ; t_{62}=5.62\right.$, $p<0.001)$.

\section{Place Conditioning Time Course After Acute Morphine Exposure}

A delayed CPA has been reported after acute exposure to morphine (Bechara et al, 1995). We next determined the time course of place conditioning after injection of $10-\mathrm{mg} / \mathrm{kg}$ morphine (Figure 5). Each group spent $\sim 50 \%$ time on the drug side during the baseline session, confirming the unbiased nature of our place conditioning procedure. ANOVA indicated a significant session $\times$ time interaction $\left(\mathrm{F}_{6,87}=4.89, p<0.001\right)$. As expected, CPP was observed immediately after morphine injection (0:00) $\left(t_{11}=2.85\right.$, $p=0.016)$, and was maintained at 2:00 $\left(t_{11}=4.29, p=0.001\right)$ and 4:00 $\left(t_{10}=3.70, p=0.004\right)$. The 4:00 time point is when we observe peak startle potentiation after this same dose of 

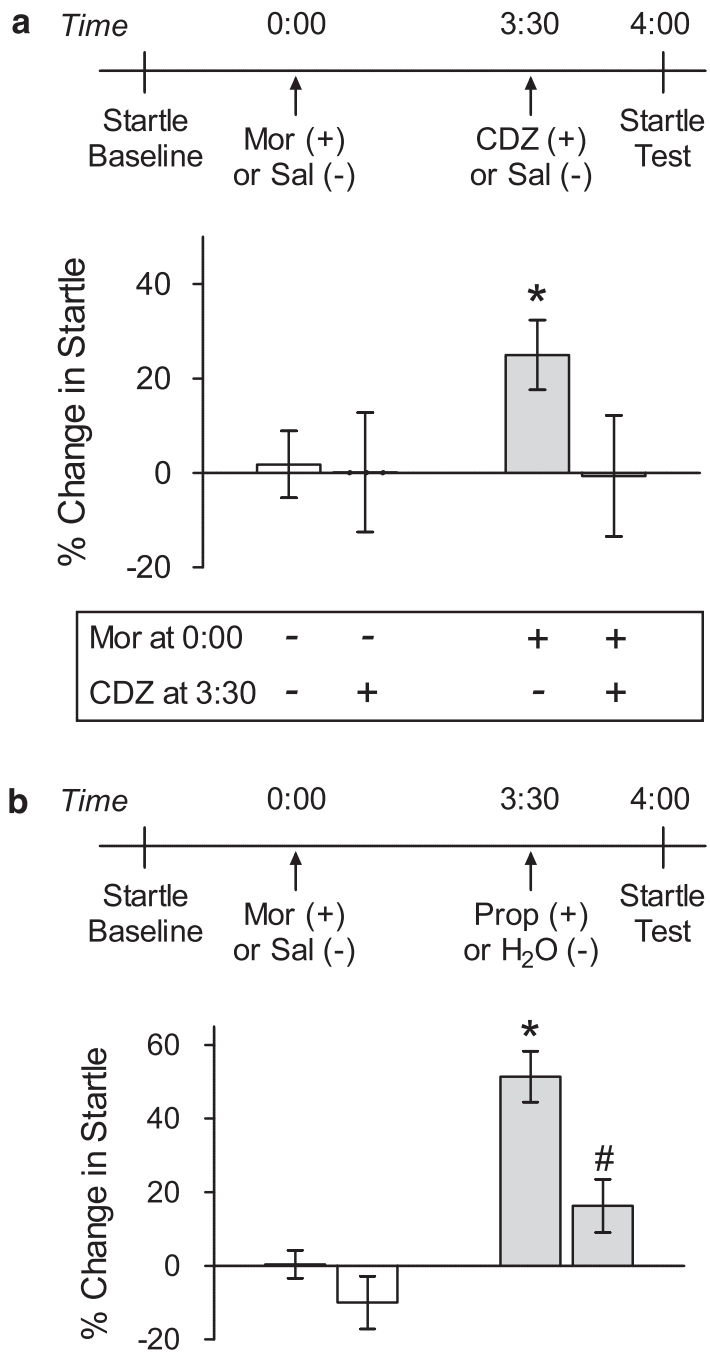

\begin{tabular}{|c|c|c|c|}
\hline Mor at 0:00 & - & + & + \\
\hline Prop at 3:30 & + & - & + \\
\hline
\end{tabular}

Figure 3 Anxiolytic drugs (chlordiazepoxide and propranolol) prevent spontaneous withdrawal-potentiated startle. (a) Experimental timeline: baseline startle was tested before initial injection of morphine (Mor; $10 \mathrm{mg} / \mathrm{kg}$ ) or saline (Sal), followed $3.5 \mathrm{~h}$ later by injection of chlordiazepoxide (CDZ; $10 \mathrm{mg} / \mathrm{kg}$ ), propranolol (Prop; $10 \mathrm{mg} / \mathrm{kg}$ ), or vehicle. Treatment combinations are shown in the box below each graph; gray bars indicate Mor injection at 0:00. (b) Results for chlordiazepoxide (16 rats/group). (c) Results for propranolol (I I rats/group). Startle was tested over 2 days using a crossover design; the initial injection changed each day in counterbalanced order, whereas the second injection was the same on both days. *Significant increase compared with saline alone; \# significant decrease compared with morphine alone.

morphine (cf. Figure 1), indicating that rats are still experiencing a state of reward when anxiety-like behavior emerges. There was no effect of place conditioning at 6:00, and a non-significant tendency for CPA at 8:00 $\left(t_{22}=1.46, p=0.16\right)$. A trend toward CPP was also observed at 10:00 $\left(t_{11}=2.18, p=0.052\right)$. There was a significant fit to fourth-order polynomial trend across time $(p=0.003)$, suggesting the emergence of aversion after the initial preference.
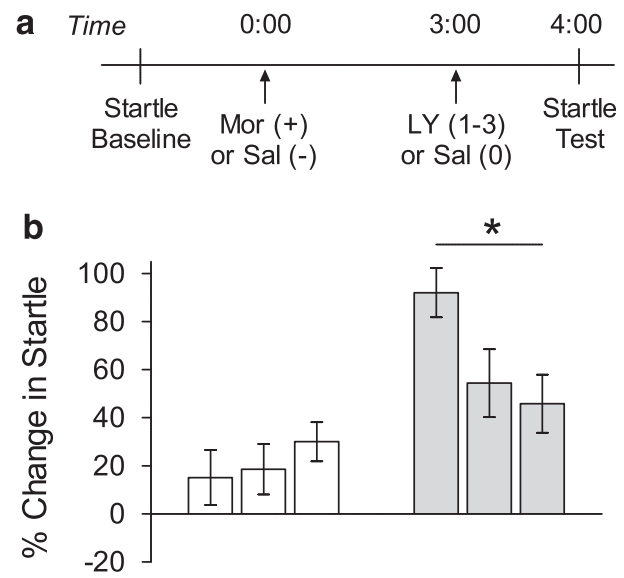

\begin{tabular}{|llllllll|}
\hline Mor at 0:00 & - & - & - & + & + & + \\
LY at 3:00 & 0 & 1 & 3 & 0 & 1 & 3 \\
\hline
\end{tabular}

Figure 4 An NMDA receptor antagonist (LY235959) attenuates spontaneous withdrawal-potentiated startle. (a) Experimental timeline: baseline startle was tested before initial injection of morphine (Mor; $10 \mathrm{mg} /$ $\mathrm{kg}$ ) or saline (Sal), followed $3 \mathrm{~h}$ later by LY235959 (LY; I-3 mg/kg) or Sal. Treatment combinations are shown in the box below the graph. (b) Results for LY235959. Startle was tested over 2 days using a crossover design; the initial injection changed each day in counterbalanced order, whereas the second injection was the same on both days. *Significant linear effect of LY235959 dose (12 rats/group).

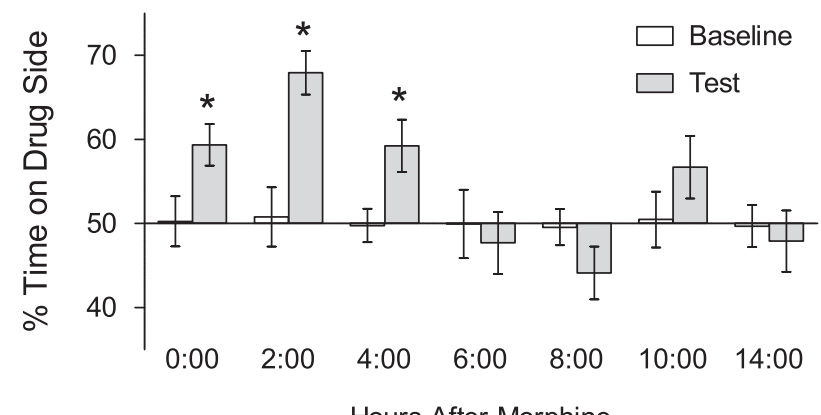

Figure 5 Place conditioning time course after acute morphine administration. Two morphine and two saline conditioning sessions (50 min each) were conducted over 4 days in counterbalanced order. Each pair of bars represents a separate group of animals. *Significant change from baseline to test ( I I-23 rats/group).

\section{Place Conditioning and Startle During Naloxone- Precipitated Withdrawal}

Because spontaneous withdrawal-potentiated startle and CPA emerged at different times after acute morphine injection, we asked whether these two behavioral effects could be dissociated under other conditions. As $2.5-\mathrm{mg} / \mathrm{kg}$ naloxone produces startle potentiation when administered $2 \mathrm{~h}$ after $10-\mathrm{mg} / \mathrm{kg}$ morphine (cf. Figure 1 ), we examined whether naloxone causes CPA under these same conditions (Figure 6a). ANOVA indicated a significant session $\times$ group interaction $\left(\mathrm{F}_{2,28}=10.04, p=0.001\right)$. Exposure to morphine alone caused CPP $\left(t_{8}=2.49, p=0.038\right)$, whereas naloxone had no effect in the absence of morphine $\left(t_{7}<1\right)$. However, naloxone administration $2 \mathrm{~h}$ after morphine caused CPA 
a Conditioning 2 hrs after morphine

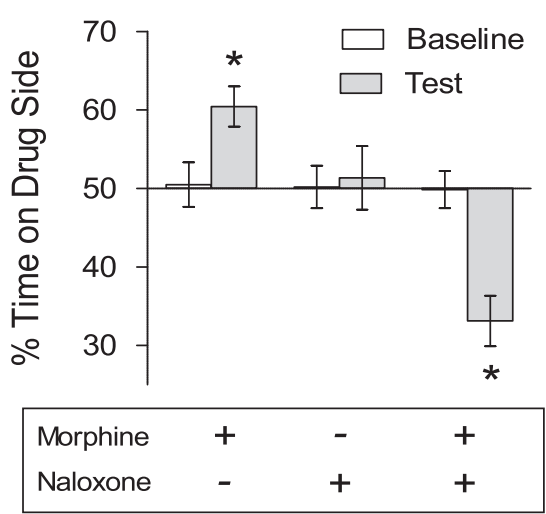

b

Conditioning 24 hrs after morphine

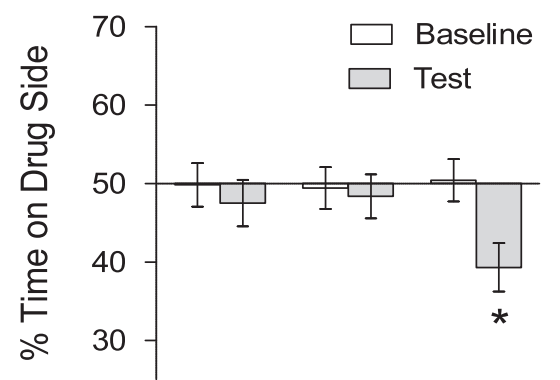

Figure 6 Conditioning with naloxone 2 or $24 \mathrm{~h}$ after morphine causes CPA. One saline and one drug conditioning session (30 min each) were conducted over 2 days. On the first day of conditioning, all rats were injected with saline or naloxone $(2.5 \mathrm{mg} / \mathrm{kg})$ immediately before exposure to the non-drug side. On the second day of conditioning, all rats received the same treatment (naloxone or saline) immediately before exposure to the drug side. Naloxone was given on both sides to control for non-specific aversive effects. Treatment combinations are shown in the box between panels a and b; each pair of bars represents a separate group of animals. (a) Place conditioning after saline or morphine $(10 \mathrm{mg} / \mathrm{kg})$ injection in the colony $2 \mathrm{~h}$ before the second conditioning session (8-14 rats/group). (b) Place conditioning after saline or morphine injection in the colony $24 \mathrm{~h}$ before the second conditioning session (15-16 rats/group). *Significant change from baseline to test.

$\left(t_{13}=3.90, p=0.002\right)$. Earlier studies have shown that naloxone still causes CPA when administered $24 \mathrm{~h}$ after a single morphine injection (Araki et al, 2004; Parker and Joshi, 1998), and we also replicated this effect (Figure 6b). At the $24 \mathrm{~h}$ time point, ANOVA indicated a trend towards a session $\times$ group interaction $\left(\mathrm{F}_{2,44}=2.15, p=0.13\right)$. Planned comparisons showed that administration of morphine followed by naloxone caused CPA $\left(t_{14}=2.47, p=0.027\right)$, whereas there was no effect of either morphine alone $\left(t_{15}<1\right)$ or naloxone alone $\left(t_{15}<1\right)$.

The effect of naloxone on acoustic startle has not been examined $24 \mathrm{~h}$ after a single exposure to morphine. We found that naloxone still produced startle potentiation $24 \mathrm{~h}$ after a single morphine injection (Figure 7$) \quad\left(t_{10}=2.57\right.$, $p=0.028)$, similar to its effect $2 \mathrm{~h}$ after acute morphine injection. Startle potentiation and CPA thus develop concurrently when naloxone is administered either 2 or $24 \mathrm{~h}$ after a single morphine injection.

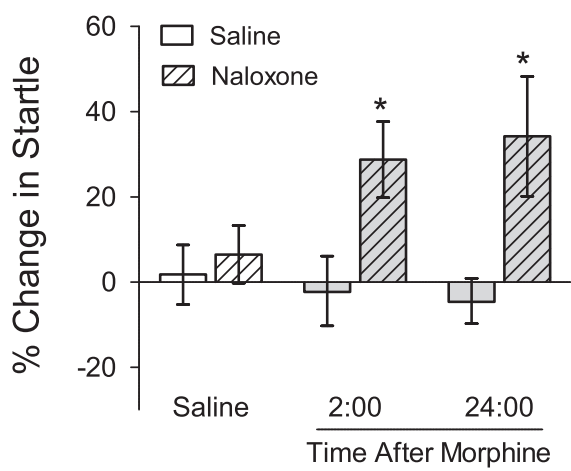

Figure 7 Effect of naloxone (2.5 mg/kg-hatched bars) on acoustic startle after injection of saline (white bars) or at different time points after a single injection of morphine (10 mg/kg; gray bars). Saline data and the 2:00 time point are reproduced from Figure I for comparison; *Significant increase compared with adjacent control group (6-16 rats/group).

\section{DISCUSSION}

Our results show that anxiety-like behavior (ie, startle potentiation) emerges spontaneously after a single exposure to morphine, seems to be related to a decrease in opiate receptor occupancy, and shares a pharmacological profile with other forms of opiate withdrawal. Startle potentiation develops before the rewarding effects of morphine have subsided, clearly dissociating increased anxiety-like behavior from decreased reward system activity. This study represents the first direct demonstration that anxiogenic and dysphoric manifestations of opiate withdrawal may be mediated by distinct neural mechanisms, which are progressively engaged during withdrawal after acute exposure to morphine.

\section{The Nature of Spontaneous Withdrawal-Potentiated Startle}

Spontaneous withdrawal-potentiated startle emerged and peaked $4 \mathrm{~h}$ after injection of $10-\mathrm{mg} / \mathrm{kg}$ morphine, consistent with our earlier report (Harris and Gewirtz, 2004a). This corresponds to a time at which morphine levels in blood and brain have declined substantially (Barjavel et al, 1995; Hipps et al, 1976), and the direct behavioral and neurochemical effects of morphine have already peaked and are returning to baseline (Babbini and Davis, 1972; Barjavel et al, 1995; Di Chiara and Imperato, 1988; Hipps et al, 1976). This suggests startle elevation emerges as morphine metabolism leads to falling drug levels and reduced opiate receptor occupancy. Startle was potentiated by naloxone administration $2 \mathrm{~h}$ after morphine, whereas morphine re-exposure delayed the onset of startle potentiation, suggesting a link between startle potentiation and decreased opiate receptor occupancy.

Spontaneous withdrawal-potentiated startle was also blocked by chlordiazepoxide and propranolol, two anxiolytic drugs shown earlier to attenuate increases in startle amplitude caused by conditioned fear cues and exposure to bright light (de Jongh et al, 2002; Risbrough et al, 2003; Walker and Davis, 2002a). Chlordiazepoxide prevents other forms of anxiety-like behavior in rodents (eg, 
Knoll et al, 2007), whereas propranolol has been shown to reduce affective signs of opiate withdrawal (Harris and Aston-Jones, 1993a,b). NMDA receptor antagonists also alleviate signs of opiate withdrawal (Harris et al, 2008; Kawasaki et al, 2005; Rasmussen, 1995). LY235959, a competitive NMDA receptor antagonist that reduces precipitated morphine withdrawal (Jones et al, 2002), produced a dose-dependent attenuation of startle potentiation. These results clearly indicate that startle elevation shares a pharmacological profile with other measures of opiate withdrawal.

\section{Relationship Between Startle Potentiation and Place Conditioning}

A delayed CPA has been observed after administration of morphine (Bechara et al, 1995), as well as other opiates (Pain et al, 2008) and other addictive drugs (Ettenberg and Bernardi, 2007; Morse et al, 2000; Pliakas et al, 2001). We assessed the time course of place conditioning after administration of $10-\mathrm{mg} / \mathrm{kg}$ morphine, and found that CPP persisted up to $4 \mathrm{~h}$ after morphine injection (see also White et al, 2005). This time course closely parallels the elevation of extracellular dopamine levels in the nucleus accumbens (Di Chiara and Imperato, 1988), consistent with the role of nucleus accumbens dopamine in generating morphine CPP (Fenu et al, 2006). A tendency for CPA emerged $8 \mathrm{~h}$ after morphine injection. Other studies have reported robust CPA $11-16 \mathrm{~h}$ after acute exposure to $20-\mathrm{mg} / \mathrm{kg}$ morphine (Bechara et al, 1995; Vargas-Perez et al, 2007), which is likely related to the differences in morphine dose and the number and timing of conditioning sessions. There was a significant fourth-order polynomial trend across time, suggesting the acute rewarding effects of morphine were followed by delayed aversive effects. We speculate that the tendency toward CPP at $10 \mathrm{~h}$ could reflect alleviation of an aversive withdrawal state.

We were surprised to find CPP $4 \mathrm{~h}$ after $10-\mathrm{mg} / \mathrm{kg}$ morphine, the same time point at which we observed peak startle potentiation. To determine whether a similar dissociation was observed under other conditions, we examined the effect of naloxone on acoustic startle and place conditioning at different times after a single morphine injection. We found that injection of $2.5-\mathrm{mg} / \mathrm{kg}$ naloxone generated CPA (as well as startle potentiation) $2 \mathrm{~h}$ after morphine injection. These results are consistent with human studies showing that naloxone can precipitate withdrawal symptoms as soon as $45 \mathrm{~min}$ after acute morphine administration (Heishman et al, 1989). Several signs of withdrawal (Eisenberg, 1982; Gellert and Sparber, 1977), including CPA (Araki et al, 2004; Parker and Joshi, 1998), are still observed when naloxone is administered 24-48 h after a single exposure to morphine. We observed both startle potentiation and CPA when naloxone was administered $24 \mathrm{~h}$ after one morphine injection, showing an additional similarity between startle potentiation and other measures of withdrawal.

A dissociation between the emergence of startle potentiation and CPA was only observed when withdrawal was allowed to unfold spontaneously. These results provide an important example in which antagonist-precipitated withdrawal does not precisely recapitulate the conditions of spontaneous withdrawal. Precipitated withdrawal is a useful experimental tool for controlling the timing of withdrawal and studying states of dependence. However, in the context of human opiate abuse, withdrawal develops spontaneously in the absence of an opiate receptor antagonist. Our findings highlight the importance of further developing models of spontaneous opiate withdrawal in rodents, to examine potential similarities and distinctions between spontaneous and precipitated withdrawal states.

In future studies, it will be important to examine the opiate receptor subtypes mediating different behavioral changes during spontaneous and precipitated withdrawal from acute morphine exposure. Specific antagonists of the mu-opioid receptor (MOR) can precipitate signs of withdrawal after chronic morphine exposure (Le Guen et al, 2003; Maldonado et al, 1992), suggesting that loss of MOR occupancy may cause spontaneous withdrawal. However, morphine also has a lower affinity for the kappa-opioid receptor (KOR) (Goldstein and Naidu, 1989), and some effects of morphine can be mediated by KOR activation (Nobre et al, 2000; Sante et al, 2000; Yamada et al, 2006). As KOR agonists produce signs of anxiety, dysphoria, and anhedonia in humans and rodents (Land et al, 2008b; Motta et al, 1995; Nestler and Carlezon, 2006; Pfeiffer et al, 1986; Sante et al, 2000; Shippenberg et al, 2007), signaling cascades triggered by KOR activation could also contribute to spontaneous withdrawal. On the other hand, KOR antagonists can in some cases exacerbate the severity of opiate withdrawal (Spanagel et al, 1994). The potential contributions of MOR and KOR could be addressed in future studies using techniques that directly measure receptor occupancy, such as autoradiography, to examine changes in the occupancy of MOR and KOR across multiple brain structures in the hours after acute morphine administration.

\section{Potential Neural Substrates For Anxiety and Dysphoria}

During spontaneous withdrawal from acute morphine exposure, startle potentiation emerges before the rewarding effects of morphine have subsided, and thus before the onset of CPA. Our data suggest that startle potentiation may be caused by decreased opiate receptor occupancy. In contrast, CPA may instead represent an opponent process to the acute rewarding effects of morphine (Vargas-Perez et al, 2007). As such, CPA may reflect a decrease below baseline activity in the mesolimbic dopamine system. This type of change has been shown during withdrawal from chronic opiate exposure (Diana et al, 1995; Rossetti et al, 1992; Spanagel et al, 1994), as well as acute amphetamine exposure (Barr et al, 2002), although we are not aware of similar studies performed after acute morphine administration. Adaptations within the reward system are thought to play a role in depression (Nestler and Carlezon, 2006), and depression-like changes during opiate withdrawal may be manifested as CPA (Vargas-Perez et al, 2007) and elevated ICSS thresholds (Liu and Schulteis, 2004).

In contrast, startle potentiation emerges while the reward system is still active, but its activity has decreased from peak levels (Di Chiara and Imperato, 1988). This suggests the anxiety-like manifestations of opiate withdrawal may be closely tied to a relative decrease in hedonic state 
(ie, a negative slope), rather than an absolute decrease below baseline. Portions of the extended amygdala, including the bed nucleus of the stria terminalis and central nucleus of the amygdala, play a general role in states of withdrawal (Koob and Le Moal, 2008) and anxiety (Walker et al, 2003), and are specifically involved in antagonistprecipitated withdrawal from acute morphine administration (Cabral et al, 2009; Criner et al, 2007; Harris et al, 2006). This involvement could result from a direct and local effect of morphine, or may be secondary to morphineinduced elevations in extracellular dopamine (Carboni et al, 2000). The specific role of these circuits in different emotional manifestations of spontaneous withdrawal will be an important topic for future research.

This framework may help explain why baseline startle amplitude is not elevated during precipitated withdrawal from chronic opiate administration (Fendt and Mucha, 2001; Kalinichev and Holtzman, 2003; Mansbach et al, 1992). These conditions produce dramatic decreases in mesolimbic dopamine system activity (Diana et al, 1995; Pothos et al, 1991; Rossetti et al, 1992) and brain reward function (Schulteis et al, 1994). The resulting depressionlike state could obscure or overwhelm the expression of anxiogenic manifestations of withdrawal. Indeed, human patients diagnosed with depressive illness do not exhibit increases in startle amplitude under conditions that normally produce startle potentiation in control subjects (Dichter and Tomarken, 2008; Forbes et al, 2005; Lang and McTeague, 2009).

\section{Implications For Addiction}

Our results clearly indicate that withdrawal is a complex and multifaceted construct. We have described distinct time courses for two specific emotional manifestations of acute withdrawal (ie, startle potentiation and CPA). The spontaneous evolution of other signs of acute withdrawal may parallel one of the time courses we have described, or may follow other unique time courses. For example, spontaneous increases in ICSS threshold have been reported $24 \mathrm{~h}$ after acute morphine exposure (Liu and Schulteis, 2004). We also note that spontaneous hyperalgesia has been observed after a single exposure to heroin (Laulin et al, 1998) or morphine (Sweitzer et al, 2004). The time course of hyperalgesia is complex, as it emerges and dissipates in the hours after opiate administration, then reappears $24 \mathrm{~h}$ later and lasts several days (Laulin et al, 1998). Thus, the various emotional and physical manifestations of spontaneous withdrawal likely result from a cascade of numerous neurobiological events, which develop and evolve as a function of time.

It is important to note that anxiety-like signs of spontaneous withdrawal may represent one of the earliest manifestations of the withdrawal syndrome, developing before CPA and changes in ICSS threshold. As spontaneous startle potentiation was delayed by re-exposure to morphine, relief or prevention of anxiety may be particularly important for motivating continued drug use. The relief of anxiety states may provide primary negative reinforcement for ongoing drug use, perhaps by maintaining dopaminergic tone within the extended amygdala, as D1 receptor antagonism in the amygdala can enhance cocaine intake, even while dopamine levels in NAc remain elevated (Hurd et al, 1997). In addition, anxiety-like states may motivate drug use because they predict the subsequent emergence of depression-like states, thus serving as secondary negative reinforcers. Finally, anxiety-like states generated by stressful experience could also contribute to stress-induced relapse, particularly given the common neural circuitry involved in stress-induced reinstatement (Shaham et al, 2003) and potentiated acoustic startle (Walker et al, 2003).

Events that occur during spontaneous withdrawal may also contribute to some of the unique effects of intermittent opiate exposure. For example, intermittent injections of morphine produce physiological changes similar to those caused by chronic stress (Houshyar et al, 2003; Houshyar et al, 2004), changes not observed when morphine is administered continuously. The acute withdrawal state that follows each intermittent morphine injection may contribute to this stress-like profile. Indeed, changes in brain activity during spontaneous withdrawal could contribute to any difference between the consequences of continuous and intermittent opiate exposure. As human drug abuse is routinely interrupted by drug-free periods (Baker et al, 2004; Dole et al, 1966), it will be important to examine whether events that occur during spontaneous withdrawal contribute to adaptations in brain function during intermittent drug exposure.

These results add to a growing number of dissociations between anxiety- and depression-like behavior under a variety of experimental conditions (Bosch et al, 2008; Land et al, 2008a; Nestler and Carlezon, 2006; Sahuque et al, 2006; Wallace et al, 2009), and raise important considerations for future research. First, signs of withdrawal develop spontaneously after just one exposure to morphine, and are likely expressed after each intermittent exposure to an opiate. This means withdrawal is not unique to the termination of chronic drug use, but is an intrinsic component of drug taking that may play an important but often neglected role in the development of addiction. Second, anxiety-like manifestations of withdrawal emerge while the animal is still experiencing a state of reward. As dysphoria and other depression-like manifestations of withdrawal likely reflect decreases below baseline in reward system activity, symptoms of anxiety and depression may develop at different times as withdrawal unfolds, which could have important treatment implications. Therapeutic interventions that ameliorate symptoms of anxiety and depression, such as KOR antagonists (Knoll et al, 2007; Land et al, 2008a; Land et al, 2008b; Nestler and Carlezon, 2006), may prove particularly effective. A clearer understanding of the neurobiological underpinnings of opiate withdrawal could potentially advance our understanding of mood and anxiety disorders, in addition to improving treatment of addiction itself.

\section{ACKNOWLEDGEMENTS}

We thank Bonnie LaCroix and Malaak Moussa for expert technical assistance, and Dr Andrew Harris and members of the Gewirtz and Thomas labs for helpful comments. This work was supported by funding from the University of Minnesota Graduate School (to PER) and Grants from 
NIDA (DA007234 and DA023750 to PER, DA019666 to MJT, and DA018784 to JCG), the Whitehall Foundation (to MJT), and NARSAD (to JCG).

\section{DISCLOSURE/CONFLICT OF INTEREST}

The authors declare that, except for income received from their primary employers, no financial support or compensation has been received from any individual or corporate entity over the past 3 years for research or professional service, and there are no personal financial holdings that could be perceived as constituting a potential conflict of interest.

\section{REFERENCES}

American Psychiatric Association (2000). Diagnostic and statistical manual of mental disorders : DSM-IV-TR, 4th edn. American Psychiatric Association: Washington, DC, xxxvii, 943 p.pp.

Araki H, Kawakami KY, Jin C, Suemaru K, Kitamura Y, Nagata M et al (2004). Nicotine attenuates place aversion induced by naloxone in single-dose, morphine-treated rats. Psychopharmacology (Berl) 171: 398-404.

Babbini M, Davis WM (1972). Time-dose relationships for locomotor activity effects of morphine after acute or repeated treatment. $\mathrm{Br}$ J Pharmacol 46: 213-224.

Baker TB, Piper ME, McCarthy DE, Majeskie MR, Fiore MC (2004). Addiction motivation reformulated: an affective processing model of negative reinforcement. Psychol Rev 111: 33-51.

Bardo MT, Bevins RA (2000). Conditioned place preference: what does it add to our preclinical understanding of drug reward? Psychopharmacology (Berl) 153: 31-43.

Barjavel MJ, Scherrmann JM, Bhargava HN (1995). Relationship between morphine analgesia and cortical extracellular fluid levels of morphine and its metabolites in the rat: a microdialysis study. Br J Pharmacol 116: 3205-3210.

Barr AM, Markou A, Phillips AG (2002). A 'crash' course on psychostimulant withdrawal as a model of depression. Trends Pharmacol Sci 23: 475-482.

Bechara A, Nader K, van der Kooy D (1995). Neurobiology of withdrawal motivation: evidence for two separate aversive effects produced in morphine-naive $v s$ morphine-dependent rats by both naloxone and spontaneous withdrawal. Behav Neurosci 109: 91-105.

Bilsky EJ, Inturrisi CE, Sadee W, Hruby VJ, Porreca F (1996). Competitive and non-competitive NMDA antagonists block the development of antinociceptive tolerance to morphine, but not to selective mu or delta opioid agonists in mice. Pain 68: 229-237.

Bosch OJ, Nair HP, Ahern TH, Neumann ID, Young LJ (2008). The CRF system mediates increased passive stress-coping behavior following the loss of a bonded partner in a monogamous rodent. Neuropsychopharmacology 34: 1406-1415.

Breiter HC, Gollub RL, Weisskoff RM, Kennedy DN, Makris N, Berke JD et al (1997). Acute effects of cocaine on human brain activity and emotion. Neuron 19: 591-611.

Cabral A, Ruggiero RN, Nobre MJ, Brandao ML, Castilho VM (2009). GABA and opioid mechanisms of the central amygdala underlie the withdrawal-potentiated startle from acute morphine. Prog Neuropsychopharmacol Biol Psychiatry 33: 334-344.

Carboni E, Silvagni A, Rolando MT, Di Chiara G (2000). Stimulation of in vivo dopamine transmission in the bed nucleus of stria terminalis by reinforcing drugs. J Neurosci 20: RC102.

Carlezon Jr WA (2003). Place conditioning to study drug reward and aversion. Methods Mol Med 84: 243-249.
Carlezon Jr WA, Chartoff EH (2007). Intracranial self-stimulation (ICSS) in rodents to study the neurobiology of motivation. Nat Protoc 2: 2987-2995.

Cole BJ, Koob GF (1988). Propranolol antagonizes the enhanced conditioned fear produced by corticotropin releasing factor. J Pharmacol Exp Ther 247: 902-910.

Criner SH, Liu J, Schulteis G (2007). Rapid neuroadaptation in the nucleus accumbens and bed nucleus of the stria terminalis mediates suppression of operant responding during withdrawal from acute opioid dependence. Neuroscience 144: 1436-1446.

Cunningham CL, Gremel CM, Groblewski PA (2006). Druginduced conditioned place preference and aversion in mice. Nat Protoc 1: 1662-1670.

de Jongh R, Groenink L, van Der Gugten J, Olivier B (2002). The light-enhanced startle paradigm as a putative animal model for anxiety: effects of chlordiazepoxide, flesinoxan and fluvoxamine. Psychopharmacology (Berl) 159: 176-180.

Di Chiara G, Imperato A (1988). Drugs abused by humans preferentially increase synaptic dopamine concentrations in the mesolimbic system of freely moving rats. Proc Natl Acad Sci USA 85: 5274-5278.

Diana M, Pistis M, Muntoni A, Gessa G (1995). Profound decrease of mesolimbic dopaminergic neuronal activity in morphine withdrawn rats. J Pharmacol Exp Ther 272: 781-785.

Dichter GS, Tomarken AJ (2008). The chronometry of affective startle modulation in unipolar depression. J Abnorm Psychol 117: $1-15$.

Dole VP, Nyswander ME, Kreek MJ (1966). Narcotic blockade. Arch Intern Med 118: 304-309.

Eisenberg RM (1982). Further studies on the acute dependence produced by morphine in opiate naive rats. Life Sci 31: 1531-1540.

Ettenberg A, Bernardi RE (2007). Effects of buspirone on the immediate positive and delayed negative properties of intravenous cocaine as measured in the conditioned place preference test. Pharmacol Biochem Behav 87: 171-178.

Fendt M, Mucha RF (2001). Anxiogenic-like effects of opiate withdrawal seen in the fear-potentiated startle test, an interdisciplinary probe for drug-related motivational states. Psychopharmacology (Berl) 155: 242-250.

Fenu S, Spina L, Rivas E, Longoni R, Di Chiara G (2006). Morphine-conditioned single-trial place preference: role of nucleus accumbens shell dopamine receptors in acquisition, but not expression. Psychopharmacology (Berl) 187: 143-153.

Forbes EE, Miller A, Cohn JF, Fox NA, Kovacs M (2005). Affectmodulated startle in adults with childhood-onset depression: relations to bipolar course and number of lifetime depressive episodes. Psychiatry Res 134: 11-25.

Gellert VF, Sparber SB (1977). A comparison of the effects of naloxone upon body weight loss and suppression of fixed-ratio operant behavior in morphine-dependent rats. J Pharmacol Exp Ther 201: 44-54.

Goldberg D (2008). Towards DSM-V: the relationship between generalized anxiety disorder and major depressive episode. Psychol Med 38: 1671-1675.

Goldstein A, Naidu A (1989). Multiple opioid receptors: ligand selectivity profiles and binding site signatures. Mol Pharmacol 36: $265-272$.

Haertzen CA, Hooks Jr NT (1969). Changes in personality and subjective experience associated with the chronic administration and withdrawal of opiates. J Nerv Ment Dis 148: 606-614.

Harris AC, Atkinson DM, Aase DM, Gewirtz JC (2006). Double dissociation in the neural substrates of acute opiate dependence as measured by withdrawal-potentiated startle. Neuroscience 139: $1201-1210$.

Harris AC, Gewirtz JC (2004a). Elevated startle during withdrawal from acute morphine: a model of opiate withdrawal and anxiety. Psychopharmacology (Berl) 171: 140-147. 
Harris AC, Gewirtz JC (2005). Acute opioid dependence: characterizing the early adaptations underlying drug withdrawal. Psychopharmacology (Berl) 178: 353-366.

Harris AC, Hanes SL, Gewirtz JC (2004b). Potentiated startle and hyperalgesia during withdrawal from acute morphine: effects of multiple opiate exposures. Psychopharmacology (Berl) 176: 266-273.

Harris AC, Rothwell PE, Gewirtz JC (2008). Effects of the NMDA receptor antagonist memantine on the expression and development of acute opiate dependence as assessed by withdrawalpotentiated startle and hyperalgesia. Psychopharmacology (Berl) 196: 649-660.

Harris GC, Aston-Jones G (1993a). Beta-adrenergic antagonists attenuate somatic and aversive signs of opiate withdrawal. Neuropsychopharmacology 9: 303-311.

Harris GC, Aston-Jones G (1993b). Beta-adrenergic antagonists attenuate withdrawal anxiety in cocaine- and morphine-dependent rats. Psychopharmacology (Berl) 113: 131-136.

Heishman SJ, Stitzer ML, Bigelow GE, Liebson IA (1989). Acute opioid physical dependence in humans: effect of varying the morphine-naloxone interval. I. J Pharmacol Exp Ther 250: 485-491.

Hipps PP, Eveland MR, Meyer ER, Sherman WR, Cicero TJ (1976). Mass fragmentography of morphine: relationship between brain levels and analgesic activity. J Pharmacol Exp Ther 196: 642-648.

Houshyar H, Gomez F, Manalo S, Bhargava A, Dallman MF (2003). Intermittent morphine administration induces dependence and is a chronic stressor in rats. Neuropsychopharmacology 28: 1960-1972.

Houshyar H, Manalo S, Dallman MF (2004). Time-dependent alterations in mRNA expression of brain neuropeptides regulating energy balance and hypothalamo-pituitary-adrenal activity after withdrawal from intermittent morphine treatment. J Neurosci 24: 9414-9424.

Hurd YL, McGregor A, Ponten M (1997). In vivo amygdala dopamine levels modulate cocaine self-administration behaviour in the rat: D1 dopamine receptor involvement. Eur J Neurosci 9: 2541-2548.

Jones KL, Zhu H, Jenab S, Du T, Inturrisi CE, Barr GA (2002). Attenuation of acute morphine withdrawal in the neonatal rat by the competitive NMDA receptor antagonist LY235959. Neuropsychopharmacology 26: 301-310.

Kalinichev M, Holtzman SG (2003). Changes in urination/ defecation, auditory startle response, and startle-induced ultrasonic vocalizations in rats undergoing morphine withdrawal: similarities and differences between acute and chronic dependence. J Pharmacol Exp Ther 304: 603-609.

Kawasaki Y, Jin C, Suemaru K, Kawasaki H, Shibata K, Choshi T et al (2005). Effect of glutamate receptor antagonists on place aversion induced by naloxone in single-dose morphine-treated rats. Br J Pharmacol 145: 751-757.

Keppel G, Wickens TD (2004). Design and Analysis : A Researcher's Handbook. Pearson Prentice Hall: Upper Saddle River, NJ. xii, 611 p.pp.

Kessler RC, Gruber M, Hettema JM, Hwang I, Sampson N, Yonkers KA (2008). Co-morbid major depression and generalized anxiety disorders in the National Comorbidity Survey follow-up. Psychol Med 38: 365-374.

Kirby KC, Stitzer ML (1993). Opioid physical dependence development in humans: effect of time between agonist pretreatments. Psychopharmacology (Berl) 112: 511-517.

Knoll AT, Meloni EG, Thomas JB, Carroll FI, Carlezon Jr WA (2007). Anxiolytic-like effects of kappa-opioid receptor antagonists in models of unlearned and learned fear in rats. J Pharmacol Exp Ther 323: 838-845.

Koob GF, Le Moal M (2008). Addiction and the brain antireward system. Annu Rev Psychol 59: 29-53.

Krueger RF (1999). The structure of common mental disorders. Arch Gen Psychiatry 56: 921-926.
Land BB, Bruchas MR, Lemos JC, Chavkin C (2008a). Distinct roles for CRF receptor subtypes 1 and 2 in producing dynorphin/ kappa opioid receptor-dependent anxiety and conditioned place aversion. Abstr Soc Neurosci 34: 187.1.

Land BB, Bruchas MR, Lemos JC, Xu M, Melief EJ, Chavkin C (2008b). The dysphoric component of stress is encoded by activation of the dynorphin kappa-opioid system. J Neurosci 28: 407-414.

Lang PJ, Davis M, Ohman A (2000). Fear and anxiety: animal models and human cognitive psychophysiology. J Affect Disord 61: 137-159.

Lang PJ, McTeague LM (2009). The anxiety disorder spectrum: fear imagery, physiological reactivity, and differential diagnosis. Anxiety Stress Coping 22: 5-25.

Laulin JP, Larcher A, Celerier E, Le Moal M, Simonnet G (1998). Long-lasting increased pain sensitivity in rat following exposure to heroin for the first time. Eur J Neurosci 10: 782-785.

Le Guen S, Gestreau C, Besson JM (2003). Morphine withdrawal precipitated by specific mu, delta or kappa opioid receptor antagonists: a c-Fos protein study in the rat central nervous system. Eur J Neurosci 17: 2425-2437.

Liu J, Schulteis G (2004). Brain reward deficits accompany naloxone-precipitated withdrawal from acute opioid dependence. Pharmacol Biochem Behav 79: 101-108.

Maldonado R, Negus S, Koob GF (1992). Precipitation of morphine withdrawal syndrome in rats by administration of mu-, deltaand kappa-selective opioid antagonists. Neuropharmacology 31: 1231-1241.

Mansbach RS, Gold LH, Harris LS (1992). The acoustic startle response as a measure of behavioral dependence in rats. Psychopharmacology (Berl) 108: 40-46.

Mendez IA, Trujillo KA (2008). NMDA receptor antagonists inhibit opiate antinociceptive tolerance and locomotor sensitization in rats. Psychopharmacology (Berl) 196: 497-509.

Morse AC, Schulteis G, Holloway FA, Koob GF (2000). Conditioned place aversion to the 'hangover' phase of acute ethanol administration in the rat. Alcohol 22: 19-24.

Motta V, Penha K, Brandao ML (1995). Effects of microinjections of $\mathrm{mu}$ and kappa receptor agonists into the dorsal periaqueductal gray of rats submitted to the plus maze test. Psychopharmacology (Berl) 120: 470-474.

Nestler EJ, Carlezon Jr WA (2006). The mesolimbic dopamine reward circuit in depression. Biol Psychiatry 59: 1151-1159.

Nobre MJ, Ribeiro dos Santos N, Aguiar MS, Brandao ML (2000). Blockade of mu- and activation of kappa-opioid receptors in the dorsal periaqueductal gray matter produce defensive behavior in rats tested in the elevated plus-maze. Eur J Pharmacol 404: 145-151.

Pain L, Oberling P, Mainsongeon M, Moulinoux JP, Simonnet G (2008). Delayed aversive effects of high-dose fentanyl. Prevention by a polyamine-deficient diet. Behav Brain Res 190: 119-123.

Parker LA, Joshi A (1998). Naloxone-precipitated morphine withdrawal induced place aversions: effect of naloxone at $24 \mathrm{~h}$ postmorphine. Pharmacol Biochem Behav 61: 331-333.

Pfeiffer A, Brantl V, Herz A, Emrich HM (1986). Psychotomimesis mediated by kappa opiate receptors. Science 233: 774-776.

Pliakas AM, Carlson RR, Neve RL, Konradi C, Nestler EJ, Carlezon Jr WA (2001). Altered responsiveness to cocaine and increased immobility in the forced swim test associated with elevated cAMP response element-binding protein expression in nucleus accumbens. J Neurosci 21: 7397-7403.

Pothos E, Rada P, Mark GP, Hoebel BG (1991). Dopamine microdialysis in the nucleus accumbens during acute and chronic morphine, naloxone-precipitated withdrawal and clonidine treatment. Brain Res 566: 348-350.

Rasmussen K (1995). The role of the locus coeruleus and $\mathrm{N}$-methyl-D-aspartic acid (NMDA) and AMPA receptors in opiate withdrawal. Neuropsychopharmacology 13: 295-300. 
Risbrough VB, Brodkin JD, Geyer MA (2003). GABA-A and 5HT1A receptor agonists block expression of fear-potentiated startle in mice. Neuropsychopharmacology 28: 654-663.

Rodriguez-Romaguera J, Sotres-Bayon F, Mueller D, Quirk GJ (2009). Systemic propranolol acts centrally to reduce conditioned fear in rats without impairing extinction. Biol Psychiatry 65: $887-892$.

Rossetti ZL, Hmaidan Y, Gessa GL (1992). Marked inhibition of mesolimbic dopamine release: a common feature of ethanol, morphine, cocaine and amphetamine abstinence in rats. Eur $J$ Pharmacol 221: 227-234.

Sahuque LL, Kullberg EF, McGeehan AJ, Kinder JR, Hicks MP, Blanton MG et al (2006). Anxiogenic and aversive effects of corticotropin-releasing factor (CRF) in the bed nucleus of the stria terminalis in the rat: role of CRF receptor subtypes. Psychopharmacology (Berl) 186: 122-132.

Sante AB, Nobre MJ, Brandao ML (2000). Place aversion induced by blockade of mu or activation of kappa opioid receptors in the dorsal periaqueductal gray matter. Behav Pharmacol 11: 583-589.

Schulteis G, Markou A, Gold LH, Stinus L, Koob GF (1994). Relative sensitivity to naloxone of multiple indices of opiate withdrawal: a quantitative dose-response analysis. J Pharmacol Exp Ther 271: 1391-1398.

Shaham Y, Shalev U, Lu L, De Wit H, Stewart J (2003). The reinstatement model of drug relapse: history, methodology and major findings. Psychopharmacology (Berl) 168: 3-20.

Shippenberg TS, Zapata A, Chefer VI (2007). Dynorphin and the pathophysiology of drug addiction. Pharmacol Ther 116: 306-321.

Spanagel R, Almeida OF, Bartl C, Shippenberg TS (1994). Endogenous kappa-opioid systems in opiate withdrawal: role in aversion and accompanying changes in mesolimbic dopamine release. Psychopharmacology (Berl) 115: 121-127.

Sweitzer SM, Allen CP, Zissen MH, Kendig JJ (2004). Mechanical allodynia and thermal hyperalgesia upon acute opioid withdrawal in the neonatal rat. Pain 110: 269-280.

Van Dyke C, Byck R (1982). Cocaine. Sci Am 246: 128-141.

Vargas-Perez H, Ting AKRA, Heinmiller A, Sturgess JE, van der Kooy D (2007). A test of the opponent-process theory of motivation using lesions that selectively block morphine reward. Eur J Neurosci 25: 3713-3718.

Walker DL, Davis M (2002a). Light-enhanced startle: further pharmacological and behavioral characterization. Psychopharmacology (Berl) 159: 304-310.

Walker DL, Davis M (2002b). Quantifying fear potentiated startle using absolute vs proportional increase scoring methods: implications for the neurocircuitry of fear and anxiety. Psychopharmacology (Berl) 164: 318-328.

Walker DL, Toufexis DJ, Davis M (2003). Role of the bed nucleus of the stria terminalis $v s$ the amygdala in fear, stress, and anxiety. Eur J Pharmacol 463: 199-216.

Wallace DL, Han MH, Graham DL, Green TA, Vialou V, Iniguez SD et al (2009). CREB regulation of nucleus accumbens excitability mediates social isolation-induced behavioral deficits. Nat Neurosci 12: 200-209.

White DA, Hwang ML, Holtzman SG (2005). Naltrexone-induced conditioned place aversion following a single dose of morphine in the rat. Pharmacol Biochem Behav 81: 451-458.

Yamada H, Shimoyama N, Sora I, Uhl GR, Fukuda Y, Moriya H et al (2006). Morphine can produce analgesia via spinal kappa opioid receptors in the absence of mu opioid receptors. Brain Res 1083: 61-69. 